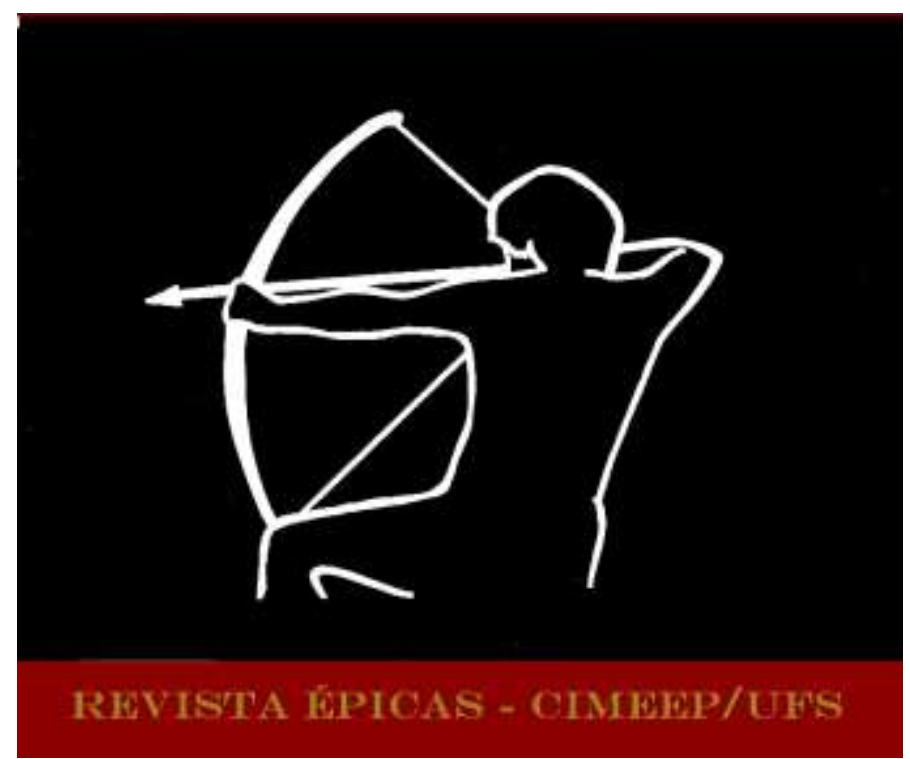

BARBOSA, Tereza Virgínia Ribeiro. Uma nação se faz com literatura. In: Revista Épicas. Ano 4, N. 7, Jun 2020, p. 1-16. ISSN 2527-080-X.

\title{
UMA NAÇÃO SE FAZ COM LITERATURA
}

\author{
A NATION IS MADE WITH LITERATURE
}

Tereza Virgínia Ribeiro Barbosa ${ }^{1}$ Universidade Federal de Minas Gerais CNPq/Fapemig

\begin{abstract}
RESUMO: O artigo pretende discutir a potência de uso dos metaplasmos em textos literários. Eles são vistos como instrumento para quebrar preconceitos culturais e linguísticos. A discussão avaliará o uso do recurso em dois autores: João Guimarães Rosa (Grande Sertão: Veredas) e Homero (Ilíada). Vamos realçar a riqueza do processo no sentido de ver tais alterações como componentes do panorama linguístico de uma nação. Sugerimos que reproduzir esteticamente a diversidade de uma comunidade linguística é ato político. Durante a discussão, utilizamos metaplasmos para, na tradução de trechos da llíada, ensaiar o que chamamos de fantasias metaplasmáticas.
\end{abstract}

Palavras-chave:

ABSTRACT: The article aims to discuss the power of using metaplasms in literary texts. They are seen as a linguistic tool to break discrimination and linguicism. The discussion will evaluate the use of the tool in two authors: João Guimarães Rosa (Grande Sertão: Veredas) and Homer (Iliad). We will highlight the richness of the process in the sense of seeing it as national linguistic panoramas. In this sense, we suggest that aesthetically reproducing of the diversity of a linguistic community is a political act. During the discussion, we used metaplasms to, in the translation of excerpts from the lliad, rehearse what we call metaplasmatic fantasies.

Keywords:

A potência dos metaplasmos será assunto deste artigo. Eles, na literatura, serão vistos como instrumento linguístico, seja para democratizar a representação artística de falares e tipos diversos de uma nação, seja para quebrar preconceitos culturais e linguísticos e estabelecer territórios estéticos ${ }^{2}$ equivalentes

\footnotetext{
${ }^{* 1}$ Professora Titular de Língua e Literatura Grega da Universidade Federal de Minas Gerais. Pesquisadora do Conselho Nacional de Desenvolvimento Científico e Tecnológico (CNPq) e da Fundação de Amparo à Pesquisa do Estado de Minas Gerais (Fapemig). E-mail de contato: tereza.virginia.ribeiro.barbosa@gmail.com.

2 De acordo com Luiz Costa Lima, Oto Marquard (1989) teria sido o responsável pela criação da expressão "território estético", quando, tratando das mudanças ocorridas no Renascimento, discorre sobre a emigração das "boas obras" do campo religioso para o
} 
a partes de uma extensão territorial heterogênea e diversificada que fala uma variante do português, a saber, o brasileiro.

A discussão avaliará o uso do recurso em textos de dois autores: João Guimarães Rosa e Homero. Nosso objetivo é realçar a riqueza do processo no sentido de vê-lo como artifício para caracterizar, incorporar e agregar diferenças. Para entender a prodigalidade do vário, Paul Ricoeur é um bom exemplo. Ao repensar o mito de Babel lido como "catástrofe linguística irremediável" (RICOEUR, 2012, pág. 35) 3 , punição de Deus e "prodigalidade nefasta", segundo Steiner (apud RICOEUR, 2012, pág. 34), o estudioso pondera:

(...) eu gostaria de retornar à interpretação do mito de Babel, que não gostaria de fechar com a ideia de catástrofe linguística infligida aos humanos por um deus ciumento de seu sucesso. Também é possível ler esse mito, como aliás todos os outros mitos de começo que levam em conta situações irreversíveis, como a constatação sem condenação de uma separação originária. (...). Para dar mais força a essa leitura, lembrarei com Umberto Eco que a narrativa de Gênesis 11, 1-9 é precedida pelos dois versículos numerados de Gênesis 10, 31-32, em que a pluralidade das línguas parece ser considerada como um dado simplesmente factual. (...).

(...) não há nenhuma recriminação, nenhuma deploração, nenhuma acusação: "IHVH - Adonai os dispersa de lá sobre a face de toda a terra. Eles cessam de construir." Eles cessaram de construir! Maneira de dizer: é assim. (...) A partir dessa realidade da vida, traduzamos! (...) Certo, há uma necessidade: se queremos começar, viajar, negociar, mesmo espionar, é preciso dispor de mensageiros que falam a língua dos outros (RICOEUR, 2012, pág. 42-45).

Gostaríamos de prolongar a citação e registrar os inúmeros bons insights do filósofo francês acerca da tarefa de traduzir, mas sejamos comedidos. Ricoeur é apenas mote para ampliar o assunto e passar de tradução para a variação linguística. Para a urgência de ouvir a fala dos outros. Do estudioso, basta-nos realçar sua proposta de ver o mundo por um lado positivo e concluir, sem demagogia, que o mito de Babel nos apresenta um ato original de pujança vital. Deste modo, entendemos que a diferença possibilita a felicidade de poder traduzir e de praticar a "hospitalidade linguística” (RICOEUR, 2012, pág. 49).

Portanto, para nossa reflexão que reúne tradução e dialetação, vamos admitir que a diversidade original é riqueza, não punição e que dentro dessa pluralidade, fartura, abundância, há não apenas diferenças entre os falares das nações, mas também, diferenças e variações dentro de um mesmo falar, de uma mesma língua; diferenças internas, fecundas e ricas.

É desse modo que julgamos, sem temor, que a incorporação de dialetos regionais - como fez Homero em seus poemas e como, defendemos, pode ser feito nas traduções de Homero - seria importante e útil para o Brasil. E, neste sentido, sugerimos a reprodução estética da diversidade linguística na tradução das epopeias gregas. Buscamos o caminho para fazê-lo através de escolhas lexicais cuidadas - a exemplo de Guimarães Rosa - sem distorções ortográficas ou "erros", que não caracterizam qualquer variedade linguística específica, mas, ao contrário, acabam por estigmatizá-las.

profano. Marquard afirma que, devido à Reforma, "as boas obras tinham de emigrar do território religioso para o recém-criado território estético, para que pudessem manter sua relevância soteriológica." (Marquard apud Costa Lima, 2008, pág. 208). Nós, ao utilizarmos a expressão, sugerimos que a literatura tem poder para criar "territórios estéticos" nacionais que, reunidos pelo sistema literário, forjam (modelam, fabricam e inventam) a identidade de um país.

${ }^{3}$ Ricoeur sempre em tradução de Patrícia Lavelle. 
Guimarães Rosa é, portanto, nosso espelho. Esboçamos traduções de excertos dos poemas homéricos comprometidas com as formas dialetais gregas neles presentes. Durante o desenvolvimento do artigo, utilizamos o recurso para, na tradução dos trechos da Ilíada, ensaiar (e testar) o que chamamos de fantasias metaplasmáticas. ${ }^{4}$ Para nós, contemplar variações locais (em relação ao vocabulário e ao uso de formas arcaicas, raras ou em desuso, na manutenção de formas concorrentes de um mesmo léxico, na observação de uma pontuação peculiar para marcar rítmicas ${ }^{5}$ próprias de cada região, etc.) em textos canônicos considerados como pertencentes à "alta literatura" é um ato político.

Vê-se como lugar-comum entre os pesquisadores admitir que a característica mais marcante dos poemas homéricos ( e que é, simultaneamente, a sua principal dificuldade) é a variedade de formas neles presentes, ${ }^{6}$ uma variedade maior do que aquilo que supomos ser possível em qualquer idioma falado individualmente (cf. MONRO, 1828, pág. 52). ${ }^{7}$ Kirk, no comentário à llíada, volume I, obra imprescindível a qualquer estudioso de épica (KIRK,1985, pág. 5), reforça a multiplicidade e a variabilidade de formas lexicais em Homero. ${ }^{8}$ Edna Maria Nascimento e Lenira Marques Covizzi têm a mesma postura acadêmica em relação a João Guimarães Rosa, assinalando-a em seu estudo, intitulado João Guimarães Rosa: homem plural, escritor singular (2001).

\footnotetext{
${ }^{4}$ Trata-se de uma prática de tradução que estamos desenvolvendo e teorizando que consiste em traduzir Homero levando em conta as variações linguísticas propostas em seu texto. O termo "fantasia" é utilizado em razão de fazermos conjecturas analógicas na tradução. Fantasia é termo da música e metaplasmático é adjetivo derivado do termo metaplasmo, sinônimo aqui de variação linguística e de alterações na estrutura vocabular. Sobre fantasia, no Dicionário Grove (tradução de E. F. Alves), lê-se: "Peça instrumental em que a imaginação do compositor tem precedência sobre os estilos e formas convencionais. (...) Os compositores do séc. XX também usaram o termo para peças instrumentais extensas (...) e para variações (...)." (Grove, 1994, pág. 311); Mário de Andrade não registra o termo "fantasia" no seu Dicionário Musical Brasileiro, prefere falar de "variação", que "consiste em repetir uma melodia dada, mudando, a cada repetição, um ou mais elementos constitutivos dela, de forma que apresentando uma fisionomia nova, ela permaneça sempre reconhecível na sua personalidade. É mesmo só no séc. XVIII que a variação se apresenta firmemente fixa nesse princípio de mudança de fisionomia e conservação de personalidade. No geral os músicos dos séculos anteriores se limitavam a variar, enriquecendo com enfeites a melodia, em vez de modificar a forma dum dos elementos dela (ritmo, tonalidade, harmonização, arabesco)." (Andrade, 1999, pág. 550).

${ }^{5}$ Ritmo aqui deve ser entendido de acordo com a proposta de Henri Meschonnic: "Mais do que o sentido, e mesmo aí onde o sentido das palavras aparentemente não é modificado, o ritmo transforma o modo de significar. O dito muda completamente, conforme levamos em conta este ritmo ou não, a significância ou não. (...) Isto não vale somente para os poemas." (MESCHONNIC, 2010, pág. 46 - Tradução de Jerusa Ferreira e Suely Fenerich). E ainda: "Os editores não sabem ainda hoje que a pontuação na poética de um texto é seu gestual, sua oralidade. E mesmo que ela seja apenas o feito dos tipógrafos da época, ela pertence à sua historicidade. É, por isso, oportuno examinar mais de perto como opera a identificação do falado e do oral que determina uma tal situação da leitura." (MESCHONNIC, 2006, pág. 23-24 - tradução de Cristiano Florentino).

${ }^{6} \mathrm{Na}$ qualidade de cronista do séc. $\mathrm{V}$ a.C., Heródoto dá testemunho da consciência dessa realidade da língua entre os gregos. Sobre o tema, cito trecho de estudo de Maria de Fátima Sousa e Silva (2009, pág. 62): “Heródoto reconhece na língua um factor político determinante. Apesar da uniformidade linguística que reconhece entre todos os Gregos, a época clássica acentua também as diferenças dialectais que caracterizam o particularismo linguístico de certas comunidades. Ao definir o mundo iónico como um xadrez étnico, político e religioso, Heródoto distingue a língua como um factor poderoso no estabelecimento de diferenças. Destaca então quatro variantes dialectais na lónia, que designa com a palavra 'alterações' (...). E passa a fazer agrupamentos ou tipos (...), que têm por base um critério geográfico: Mileto, Miunte e Priene, todas situadas na Cária, 'falam do mesmo modo', ou seja, 'usam o mesmo dialecto' (...); vem depois o grupo que se situa na Lídia (Éfeso, Cólofon, Lébedo, Teos, Clazómenas e Foceia), 'cuja língua não tem nenhuma afinidade com as anteriores' (...), mas que 'entre si, usam a mesma língua' (...); por fim, as ilhas de Samos e Quios, e Eritreia, no continente, repartem-se da forma seguinte: Quios e Eritreia, situadas frente a frente, falam o mesmo dialecto (...), e Samos 'um que é só seu' (...)."

7 "The most striking characteristic, and the main difficulty, of the Epic dialect is the variety of forms which it employs, a variety greater than we can suppose possible in any single spoken language." Todas as traduções, quando não mencionado o autor, são de nossa responsabilidade.

8 "The language of the poems, as has been remarked, is an artificial amalgam of words, constructions and dialect-forms from different regions and different stages in the development of Greek from the late Bronze Age until around 700 B.C."
} 
Numa visão panorâmica, cartográfica, que, de caso pensado, como o Google Maps, faz "vista grossa" para as singularidades, mãos de direção no trânsito e outros detalhes, ousamos afirmar que a llíada e a Odisseia, resultantes da costura de múltiplas identidades locais do mundo helênico, se assemelham muito ao Grande Sertão: Veredas pelo menos em um aspecto: ambas se configuram como um pandemônio lexical, que se realiza através do encontro, quase natural, de formas dialetais anacrônicas - no grego, com predominância do jônico; no português, prevalecendo o mineirês. Essas formas variantes e variáveis atuam em harmonia, são tal qual rio caudaloso e fluido, de altíssima temperatura poética, magma que, advindo da profundidade criadora do substrato de uma possível língua geral humana (e quase divina, como ousaria propor Walter Benjamin, nA Tarefa do Tradutor) faz ressurgir novas formas e recupera significados acumulados ao longo de um curso temporal de longo alcance.

Referendam a impressão relatada por nós muitos pesquisadores da área dos estudos linguísticos e da literatura comparada; apontamos, porém, para um caminho que se situa entre o literário, o filológico e o linguístico, ou melhor, traçamos um entreposto que opta por entrelaçar filologia do grego antigo, estudos literários e língua e literatura brasileira. Neste domínio, seguimos o percurso de Elizabeth Hazin, Walnice Nogueira Galvão, Maria Célia de Moraes Leonel, Teresinha Souto Ward, Edna Maria do Nascimento, Christian Werner e Patrizia Colina Bastianetto, entre outras e outros.

Qualquer pesquisador que se volte para dois monumentos literários como a llíada e o Grande Sertão: Veredas $^{9}$, sem dificuldade achará neles inúmeras vogais duvidosas, acomodações rítmicas inusitadas, duplicações sintáticas e sonoras, metáteses, assimilações e dissimilações imprevisíveis num mesmo conjunto que, por sua vez, está registrado em língua culta de sensibilidade e beleza extraordinária. Recordamos alguns

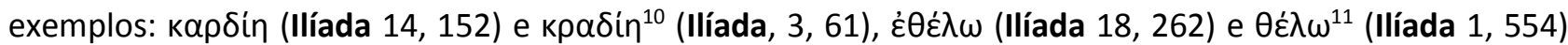
para o grego e "ínterim" e "intrim” (ROSA, 2009, vol. 2, pág. 42) ${ }^{12}$, “choupã” e "choupana” (ROSA, 2009, vol. 2, pág. 42) para o brasileiro.

E são tantas paragoges, aféreses, síncopes, vocalizações, consonantizações, apofonias, metafonias reunidas que se tem a sensação de ter sido capturado o falar natural humano em fluxo contínuo; o leitor/ouvinte é inopinadamente surpreendido pela miríade de variantes e, por isso, depara com um ritmo vertiginoso e pensa estar cara a cara com o narrador e frente a frente com a guerra, quer no cenário arcaico do cerco de Troia, quer no Sertão brasileiro.

\footnotetext{
${ }^{9}$ A partir de agora citado como GSV.

$10=$ coração.

11 = quero.

12 Sobre o vocábulo não dicionarizado "intrim", Nei Leandro de Castro (1982, pág. 120) escreve: "INTRIM - Inteirinho. Grafia da transformação fonética por que passou o termo na linguagem sertaneja: inteirinho/ interim/ intrim (Cf. M. C. Proença, TGS)"; Nilce Sant'Anna Martins (2001, pág. 276) registra: “Prov. corruptela de inteirinho.”. O significado sugerido, entretanto, não se encaixa de forma exclusiva com o contexto da narrativa, a saber, "O poço abria redondo, quase, ou ovalado. Como no recesso do mato, ali intrim, toda luz verdeja. Mas a água, mesma, azul, dum azul que haja - que roxo logo mudava. A vai, coração meu foi forte." Nossa proposta de leitura: "intrim" corruptela de "ínterim", do latim (adv. de tempo), utilizado como o adv. de lugar "intra" também do latim. 0 Oxford Latim Dictionary cita "*intrim" (pág. 954/intrinsecus) como forma hipotética de "inter".
} 
Deste modo, se, como afirma Zumthor (1993, pág. 193), "o texto escrito, uma vez que subsiste, pode assumir plenamente sua capacidade de futuro" e "o texto oral não pode, pois está muito estritamente subjugado pela exigência presente da performance", o texto escrito que simula o oral (através dos metaplasmos e do estilo formular) participa dos efeitos de ambos (escrito e oral) e vai além, já que se situa no passado (pelo arcaísmo formular, pela escritura anterior que o fixou, etc.), no futuro e igualmente no presente.

Mas escrever literatura com metaplasmos é arriscadíssimo, exceto para gênios capazes de condensar em si a expressão de um povo. Muitos autores, elogiados por alguns, execrados por outros, se serviram de metaplasmos. Recuperemos excertos de discussão e crítica em obra de Teresinha Ward para iniciar o assunto. Ela comenta o uso de metaplasmos em textos de Bernardo Guimarães (A escrava Isaura, 1875) e Coelho Neto (Rei negro, 1914). Nos dois casos, podemos supor a procura deliberada por registrar graficamente uma pronúncia comum, intermediária ou cambiante, livre de censura poética no uso de formas distintas do português padrão. Há também em ambos uma desconstrução da ideia de escrita e da noção de oralidade. Todavia, o simples ato de escrever o que não é corrente no escrito marca uma opção nem sempre bem-sucedida. Para o primeiro, depois de estudar um pequeno trecho de conversa entre Isaura e Rosa, Ward comenta:

Em que língua falam as escravas? Nota-se que não aparecem representados os diferentes níveis sociolinguísticos que estariam presentes na situação real. O narrador e as escravas falam a mesma variedade do português. Apesar de, com outros autores românticos, incorporar alguma sugestão de oralidade (...) Bernardo Guimarães apresenta em A escrava Isaura, uma visão utópica e altamente idealizada do cenário e personagens. Os escravos falam um português culto-literário, indicando, talvez, a atitude do autor, o chamado "the new country syndrome" ou uma forma de compensação pela pobreza material e o atraso cultural do país (WARD, 1984, pág. 25).

Para o segundo, Rei Negro de Coelho Neto, de forma mais contundente, a pesquisadora afirma:

\begin{abstract}
Embora esta passagem reproduza também a voz do narrador e de escravos no interior do Brasil, os escravos de Coelho Neto falam numa língua "realista-naturalista" com a representação literal do discurso que se desvia da norma e é considerado "inferior". Há reprodução de formas populares antigas como ansim, interjeições como uai, representações ortográficas de variações fonética, reduções de tipo guënta por aguenta, transposições (drumi por dormir), elipse do artigo ("Dia não chega"), todas formas muito comuns na língua oral do interior, algumas representadas no discurso escrito pela primeira vez. Ora, na ansiedade de documentar ou de dar autenticidade linguística, Coelho Neto exagera o fenômeno, assinalando como dialetais várias pronúncias comuns na fala de pessoas "educadas". (...) Nota-se também que se a fala da escrava é quase incompreensível, a língua do narrador, cheia de palavras difíceis, tão característica da prosa de Coelho Neto, não pode ser mais facilmente compreendida. A dissociação da fala do narrador da fala dos personagens contribui para realçar a fala do personagem e sugerir que o dialeto representado se distancia mais do português padrão do que realmente o é, reforçando assim o estereótipo comum nas literaturas regionalistas (WARD, 1984, pág. 26).
\end{abstract}

Lidar com variantes linguísticas como elemento estético não é simples; simular uma composição complexa de possibilidades de uso com variadíssimas interpretações e influências e nunca, jamais, um universo estanque, congelado ou fossilizado é expressão de habilidade máxima. Guimarães Rosa, exemplo mais 
próximo de nós brasileiros, harmoniza falas na narração de Riobaldo. Como autor do Riobaldo, ele igualmente se mostra consciente da variação na fala de seu personagem, não fantasia, busca o real e usa o que o povo usa, convive e emprega tanto "difícil" quanto "difícel", porque as duas formas existem e representam o brasileiro que fala ora uma, ora outra. Contudo, o expediente é "peixe vivo no moquém"13:

De primeiro, eu fazia e mexia, e pensar não pensava. Não possuía os prazos. Vivi puxando difícil de difícel, peixe vivo no moquém: quem mói no asp'ro, não fantasêia. Mas, agora, feita a folga que me vem, e sem pequenos dessossegos, estou de range rede. E me inventei neste gosto de especular idéia (ROSA, 2009, vol. 2, pág. 8).

Todavia, ciente e consciente dos riscos, para estabelecer diferenças maiores e firmar denúncias, o escritor diplomata usa também os recursos de Coelho Neto e Bernardo Guimarães e destaca um caso de clara discriminação deliberada, os catrumanos.

Um deles sobressai pela fala: "Dou de comer à mea mul'é e trêis fi'ó, em debaixo de meu sapé. (...)" O acúmulo em uma sentença de elementos que se desviam do português padrão cria o contraste necessário para destacar o discurso catrumano (...). (...) Como o discurso dos demais personagens, inclusive do narrador, utiliza alguns dos mesmos elementos, se bem que de forma mais esparsa, faz-se necessário exagerar sua representação para criar o contraste linguístico e daí social, entre os dois grupos representados. Devido à infrequência de casos como estes em Grande Sertão: Veredas, seu emprego confere-Ihe uma significação especial. É difícil criar uma impressão de dignidade moral e valor em personagens que falam uma língua que se diferencia não apenas do português padrão (do leitor e do autor) mas também da fala dos demais personagens. Usando um acúmulo de traços linguísticos estigmatizados, chama-se a atenção para o tipo de pessoa que Riobaldo chefiava e sugere-se a decadência da chefia sob seu comando (WARD, 1984, pág. 31).

Também Homero tem destaques, Tersites é um exemplo. Trata-se de uma personagem que se destaca no

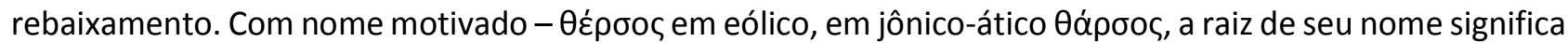
tanto "audácia", "coragem" quanto "temeridade", "imprudência". De acordo com Chantraine, "o vocábulo,

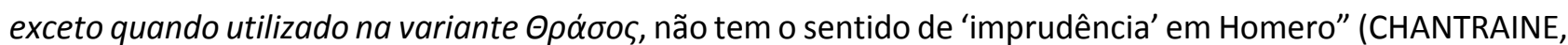
1963, pág. 20, grifo nosso). ${ }^{14}$

O nome de Tersites deve, então, tomar-se em grande parte, pelo sentido que ele implica, sendo algo como "o audacioso, o intrépido". Ele não foi criado para designar o herói homérico. No entanto, parece que lhe convém perfeitamente. Tersites, o intrépido: sim, mas em palavras apenas

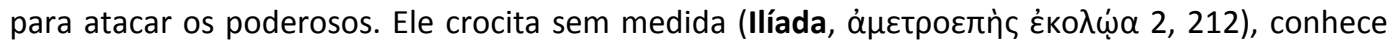
palavras desagradáveis para atacar reis, cobre Agamenão com insultos. Feio e quase aleijado, ele retoma, em tom quase vulgar as acusações que Aquiles lançou ao rei dos reis no primeiro canto (...) (CHANTRAINE, 1963, pág. 22) $)^{15}$.

\footnotetext{
13 MARTINS, 2001, pág. 339: “MOQUÉM. 'peixe vivo no moquém: quem mói no asp'ro, não fantasêia.' / Grelha de varas para assar ou secar carne ou peixe. // Bras., do tupi. A expr. 'peixe vivo no moquém' indica figuradamente 'apuros, dificuldades, atribulações'. 14 "diversement orienté, l'audace pouvant être du courage, mais aussi de la témérité, et aussi de l'impudence. Or chez Homère le mot ne s'applique jamais à l'impudence. Dans un effort de répartition des emplois, l'attique utilise Đápбos au sens de "confiance en

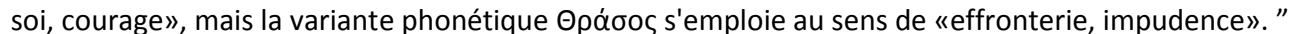

15 "Le nom de Thersite doit donc se prendre en bonne part, le sens qu'il implique étant quelque chose comme " l'audacieux, l'intrépide». II n'a pas été créé pour désigner le héros homérique. Toutefois il apparaît qu'il lui convient à merveille. Tersites l'intrépide

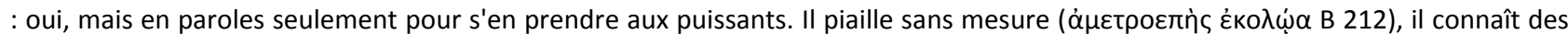
mots malséants pour s'attaquer aux rois, il couvre Agamemnon d'injures. Laid et quasi infirme, il reprend sur un ton presque vulgaire

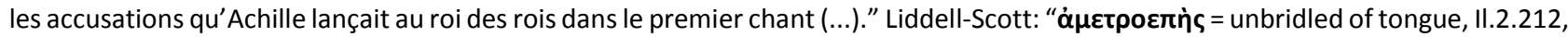
Ph.1.616." Liddell-Scott não restringe interpretações, se o termo se aplica ao uso moral, ético, material ou técnico, isto é, fala sem métrica, sem ritmo adequado.
} 
Segundo Stuurman (2004, pág. 183), que segue orientação de Chantraine, o personagem, disforme, quase sem cabelo, ombros caídos e pernas arqueadas, para além de seu nome motivado, "é retratado como homem de baixa posição social, não tem patronímico, nem lugar de origem. Tersites é, literalmente, um homem de nada; o fato de ele se dirigir à assembleia sem respeitar o ritual do cetro que autorizava a fala para os participantes lança dúvidas sobre a legitimidade de sua intervenção." ${ }^{16}$

Richard Martin, em texto de 1989, aponta um particular significativo para nós. Comparando o texto da fala de Nestor e Tersites, ele observa que a fala deste é quase despida de métrica em comparação com outros heróis medianos. ${ }^{17}$ De acordo com Martin, "se realizada em voz alta, a fala nos impressiona e chega até nós como um texto que carece de maciça 'correptio'18 , a redução de vogais longas e ditongos do valor métrico habitual forma uma sílaba 'pesada' no hexâmetro, em comparação com uma de valor breve, 'leve' . Além disso, o trecho que está igualmente carregado de sinizese (a combinação de sons de vogais normalmente separados para produzir um único $)^{19}$ cria o mesmo efeito auditivo: Tersites engole suas palavras." (MARTIN, 1989, pág. 112)20 O discurso de Tersites, se comparado com o de Nestor, é o que mais necessita de correções métricas. ${ }^{21}$ Martin grifa trechos que demandariam correptio, os quais, no parecer do

\footnotetext{
16 "He is portrayed as a man of low social standing. He has no patronym and no place of origin. Thersites is, literally, the man from nowhere; The fact that he addresses the assembly without holding the ritual speaker's scepter casts doubt on the legitimacy of his intervention."

17 "Thersites is quite literally 'without meter' in his performance, markedly more so than the average hero."

${ }^{18}$ Correption (HALPORN, OSTWALD, ROSENMEYER, 1963, pág. 12): "In epic hexameters, hiatus between words is more common than in other meters. Where hiatus occurs, a long final vowel or diphthong is often shortened metrically. This is called epic correption." [Nos hexâmetros épicos, o hiato entre as palavras é mais comum do que em outros metros. Onde ocorre o hiato, uma vogal final longa ou ditongo é geralmente encurtada metricamente. Esse [encurtamento] é chamado de correptio épica.]. (WEST, 1987, pág. 14): In epic, elegy, and some lyric a final long vowel or diphthong is usually shortened when the next word begins with a vowel

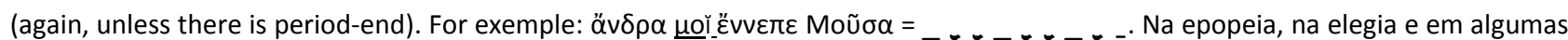
líricas, uma vogal longa final ou ditongo é, geralmente, encurtada quando a próxima palavra começa com uma vogal (novamente,

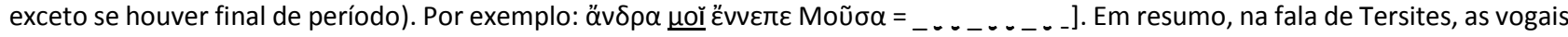
longas seguidas de ditongos, para se adequarem ao metro, devem ser encurtadas.

${ }^{19}$ Sinizese (WEST, 1987, pág. 14): "sometimes adjacent vowels are run together as one syllable. This is variously called synecphōnēsis, synizēsis, synaloepha or crasis. It may or not be indicated graphically. It is commonest when the first word is a monosyllable (...)" [às vezes vogais adjacentes são executadas juntas como uma única sílaba. Isso é chamado de sinecfonese, sinizese, sinalefa ou crase. Pode ou não ser indicado graficamente. É mais comum quando a primeira palavra é um monossílabo (...)]. O fenômeno é também chamado, no Aulete Digital, de sinérese, contração.

20 "If performed aloud, the speech strikes us as containing massive correption, the reduction of long vowels and diphthongs from their usual metrical value forming a 'heavy' syllabe in the hexameter, to a 'light', short value. In addition, synizesis (the combining of normally separate vowel sounds to produce one) produces the same auditory effect: Thersites slurs his words."

${ }^{21}$ Os poemas homéricos são literatura escrita de base oral calcada em fórmulas. Segundo Mark W. Edwards (1986, pág. 91), "[t]he essence of a formula is repetition, so it must be a 'repeated word-group,' and 'the use of one word created a strong presumption that the other would follow. This degree of mutual expectancy I choose as the best differentia of the formulaic word-group.' The word-group remains the same formula despite changes in metrical shape of its component words caused by elision or correption, inflection, shifts in meaning, changes in prefixes of suffixes, or use of alternative forms of word-stem. The formula also remains the same despite changes in the word-group arising from rearrangement of the word-order, the separation of constituent words, and the insertion, omission, or change of particles or prepositions. A formula is also capable of extension by the addition of further terms." [A essência de uma fórmula é a repetição, assim carece haver um 'grupo repetido de palavras' e 'o uso de uma palavra que crie uma forte presunção de que a outra a siga. A esse grau de expectativa mútua indico como a melhor distinção de um grupo de palavras formulares.' O grupo de palavras é a mesma fórmula, apesar de mudanças na forma métrica de suas palavras componentes, causadas por elisão ou correção, inflexão, mudanças de significado, mudanças nos prefixos, de sufixos ou uso de formas alternativas de radical de palavras. A fórmula também permanece a mesma, apesar das mudanças no grupo de palavras decorrentes do rearranjo da ordem, da separação das palavras constituintes e da inserção, omissão ou alteração de partículas ou preposições. Uma fórmula pode também somar acréscimos pela adição de outros termos nela.]
} 
helenista, são 'slurs', 'ligaduras', prolongamentos exagerados, sons desarticulados. A fala de Tersites é esta

(Ilíada, 2, 225-242):

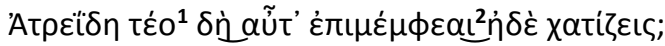

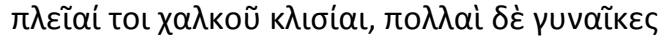

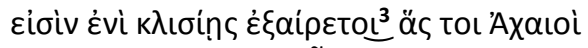

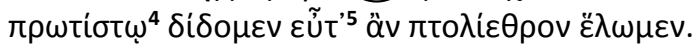

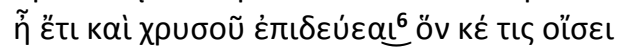

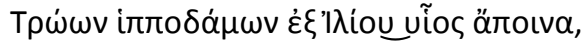

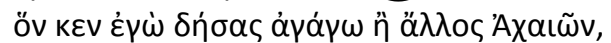

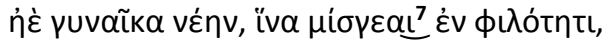

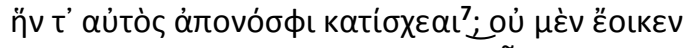

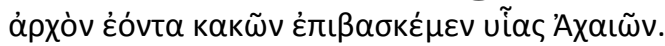

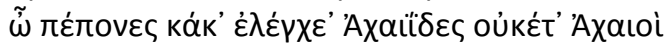

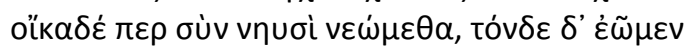

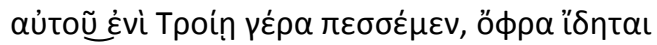

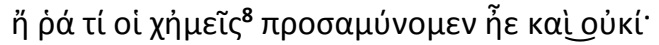

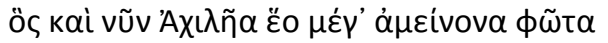

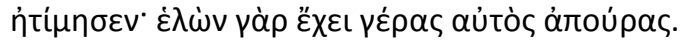

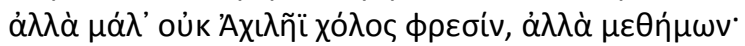

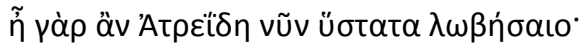

O leitor observe, por favor, algumas poucas notas que inserimos no texto grego. Elas são indicadores para marcar alguns expedientes tomados na tradução na impossibilidade de lidar com a métrica de longas e breves no português e, destarte, não poder contar com a correptio épica como característica de Tersites. Perdendo a correptio, optamos por usar o efeito da sinizese (cf. nota de rodapé 19) marcada na tradução por itálico. Além disso, observamos igualmente as formas dialetais. Algumas foram traduzidas com formas que geram efeitos similares no português, outras - as que não conseguimos encontrar formas similares ou análogas foram compensadas em situações distintas. Apresentamos nossa tradução naquilo que chamamos de fantasia metaplasmática e comentamos algumas escolhas a seguir. Antes, porém, eis a tradução:

Fil'd'Atreu, t'entouras e instas o'tra vez contra? Tens tuas tendas lotadas de cobre, muitas donas joeiradas dentro das tendas, as que os Aqueus de primaríssimo demos, ah, sim, que vilas tombamos. Hê, o mais ó, careces é d'ouro que um lá dos troas-doma-potro, por um fil'd' Ílion, livrança desse, um q'eu, ou um dos Aqueus, tivesse preado e trazido, ou por uma dona-moça boa pra mistura na cama, que, de apartado, reténs só pra ti mesmo! Não convém pra um q'é chefe trazer vasca pr'os fil's d'Aqueus. Ô carniça podre, vergonha d'Acaias não d'Aqueus, co'as naus singremos rumo à casa, leixemos este aí comer as prendas dele em Troia, modos q'ele aprenda o que valemos - ou não - nosotros. Ele qu'ind'agora Aquiles, luzeiro mui mor q'ele, afrontou no que, pra si e pra longe dele a tença rapinou. Ma nem num tinha mes'no imo do Aquileu tanta raiva, foi-se! Se não, fil'd'Atreu, derradeiro afronte era o teu! 
Notas de tradução referenciadas no texto grego

${ }^{1}$ tع́o - genitivo do pronome de 2 a pessoa, singular. Traduzido por "te", com a perda do efeito do dialeto dórico que foi compensada na aglutinação (ou crase, sinizese em sentido lato) "fil'd'Atreu".

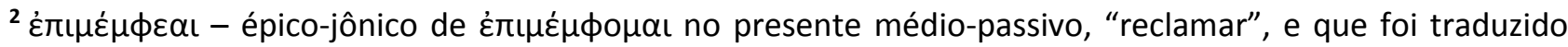
como "entourar". Para "entourar "o Aulete Digital registra dois significados: 1. SC Juntar (touros) em rebanho no período da reprodução [td.] 2. Lus. Amuar(-se), zangar(-se) [td. int.] [F.: en - + touro + -ar]." A escolha foi regida em razão de "entourar", no sentido secundário, ser pronominal e corresponder ao significado indicado no texto grego; todavia, não se deve desprezar o primeiro sentido, que agrega leituras: Agamêmnon = touro inseminador. Observe-se que - tendo Guimarães Rosa como espelho - utilizamos de uma sintaxe pouco usual na escrita, procedimento que se encaixa na noção de ritmo de Henri Meschonnic.

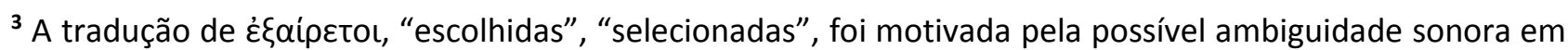
uma performance oral: "joeiradas" $\approx$ "joelhadas" = mulheres escolhidas a seu dispor.

${ }^{4}$ Utilizamos de um superlativo derivado de "primário" em lugar de "primeiro" para causar estranhamento.

${ }^{5} \mathrm{~A}$ conjunção temporal $\varepsilon u \tilde{\tau} \tau \varepsilon$ foi traduzida de modo a ter leitura escrita (ah, sim...) e auditividade (assim) diferentes, mas acumulativas. Na leitura escrita, a expressão pende para o constativo exclamativo, na auditividade ela funciona também como marcador temporal.

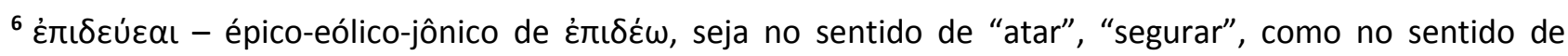
"carecer". A forma está no presente médio-passivo, sugerindo interesse escuso de Agamêmnon. Aqui há uma

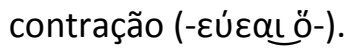

${ }^{7}$ Segundo Monro (1929, pág. 265), algumas vezes, uma sílaba breve seguida por uma cesura é tratada como longa; ainda de acordo com ele, isso dificilmente ocorre exceto quando há uma pausa de sentido. Esse é o

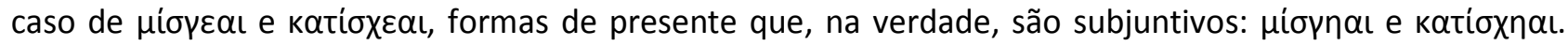
Observe-se que esse fenômeno raro ocorre duas vezes em poucos versos, o que demonstra uma certa idiossincrasia da fala de Tersites, a qual marcamos através de inúmeras sinizeses.

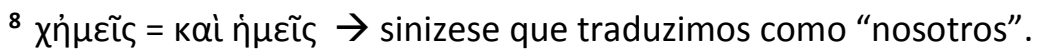

Deixemos o caso caricato de Tersites e voltemo-nos para narrativas mais coletivas, onde os dialetos funcionam mais harmoniosamente. Ponto crucial do nosso inventar: tornar-se único ainda que múltiplo e especular ideia acerca da potência dos metaplasmos nas línguas é o que agora passamos a fazer a partir da tradução da abertura do canto 21 , a fabulosa peleja de Aquiles contra o rio Xanto em razão da perseguição do herói aos troianos, que tentam, desesperada e desabaladamente, escapar pelo curso fluvial. Vejamos os cinco primeiros versos.

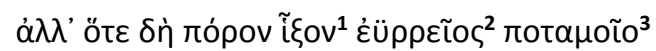

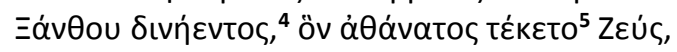

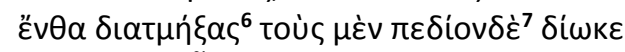

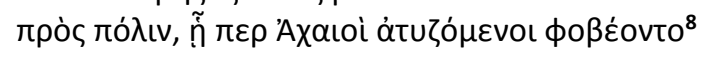




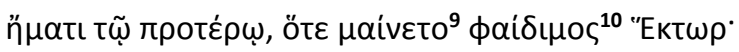

Daí no que arrivaram o raso do rio'scorredoso, do Xanto orbital que Zeus imortal jaculou, ali, desmeiados, caçava uns planura afora rumo à vila, pr'onde uns aqueus desvairados se visparam dia antes, quando se malucou Heitor galarim!

${ }^{1}$ No primeiro verso do canto, destacamos a forma ĩ ६ov. Um aoristo arcaico (sigmático e com vogal temática) de îkw. Estratagema linguístico análogo, no português, seria usarmos, como fazem as crianças, "eu sabo" em lugar de "eu sei", "ele fezo" em lugar de "ele fez" ou "ela bobia" em lugar de "ela bobeia". Rosa provoca síncope na palavra áspero (asp’ro) e propõe "fantasêia" por "fantasia". Chantraine discute a forma no §208 da Morphologie (1984). Seria uma mistura de imperfeito e futuro, um desiderativo antigo ou invenção da épica? Para simularmos o estranhamento homérico na tradução, utilizamos um arcaísmo português, "arribar", com um metaplasmo inventado que remete à forma francesa "arriver". Guimarães Rosa foi quem deu a pista: "'Trovoeira. Que os trovões a mau retumbavam. - 'Tá nas tosses...' - um daqueles enxadeiro falou. Pobre dos passarinhos do campo, desassisados." (grifo nosso. ROSA. Campo Geral, vol. 1, 2009, pág. 288). Podemos citar ainda outro trecho: “Aí Zé Bebelo não discrepou pim de surpresa, parecia até que esperava mesmo aquele voto. - 'De todo poder? Todo o mundo lealda?' - ainda perguntou, ringindo seriedade. Confirmamos." (grifo nosso. ROSA. GSV, vol. 2, 2009, pág. 60).

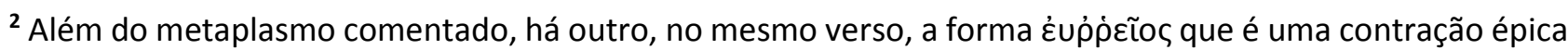

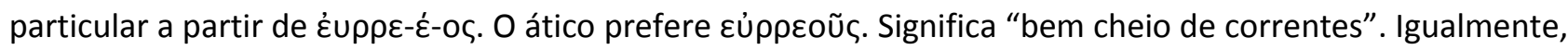
para marcar estranhamento épico, optamos por forma inspirada em adjetivo dicionarizado pouco usual, "corredoso", em lugar de "repleto de correntezas" ou de "belas correntes". Vale novamente conferir o uso do recurso semelhante em Rosa, com uso de sufixo incomum: "Dito começava a dormir de repente, era a mesma coisa que Tomezinho. Miguilim não gostava de pôr os olhos no escuro. Não queria deitar de costas, porque vem uma mulher assombrada, senta na barriga da gente. Se os pés restassem para fora da coberta, vinha mão de alma, friosa, pegava o pé." (grifo nosso. ROSA. Campo Geral, vol. 1, 2009, pág. 288); ou ainda, "Ele avermelhava os olhos? Mas com o cirro e o vidrento. Coração me apertou estreito. (grifo nosso. ROSA. GSV, vol. 2, 2009, pág. 53) O escritor evita as formas habituais mais previsíveis, como "friorenta", "frienta", "friolenta" e "frígida", para adotar uma forma que traz a convergência do termo "furiosa". Já o termo "vidrento", regularmente dicionarizado, não remete apenas a "vidro", o que poderia ter sido obtido pelos adjetivos "vítreo", "vidrado", "vidrino" e "vidroso", mas significa "melindroso, suscetível, quebradiço, agastadiço, melindroso", com a valiosa vantagem adicional de ser um metaplasmo para VI DENTRO.

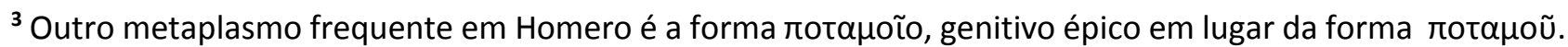
Ocorreu-nos para marca na tradução o índice de epicidade: associar a palavra "rio" e seu adjetivo inventando uma prótese 'es' para correntoso. "rio'scorrendoso" = "rio escorre/ correntoso".

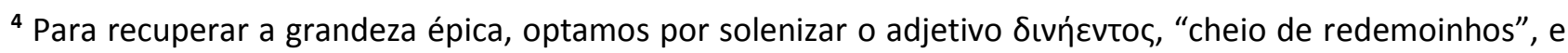
traduzi-lo com o léxico "orbital", que remete à órbita dos astros e sugere acúmulo e magnitude ou, ainda, 
parentesco com os deuses/astros, tendo em vista que Xanto é um rio-deus. A exemplo de "al" como sufixo de acúmulo, em Rosa e de uso corrente na língua: "Vez, deram até tiros: mas nada não era, só um boi loango, com muita fome e pouco sono, que veio sozinho pastando e deu a cara comprida, ali foras d'hora, no capinzal bom. (grifo nosso. ROSA. GSV, vol. 2, 2009, pág. 161) e "Ao que, com João Goanhá de testa-chefe, saímos, uns cinqüenta, pegar uma tropa de cargueiros dos bebelos, que vinham ao descuidado, de noite, no BentoPedro - lugar num braço de brejo, arrozal." (grifo nosso. ROSA. GSV, vol. 2, 2009, pág. 156) e mais "Sentamos, por fim, num lugar mais salientado, com pedras, rodeado por áspero bamburral." (grifo nosso. ROSA. GSV, vol.2, 2009, pág. 71)

${ }^{5}$ É um aoristo passivo com aférese do aumento. A voz passiva é mais frequente em relação ao pai, a voz ativa em relação à mãe (cf. SIDGWICK, 1880, pág. 39). Na tradução utilizamos um verbo associado à força masculina de fecundação, "ejacular", com aférese do "e". A título de exemplo do Rosa: "Disparo que eu dava, era catando mover alheio, cujo descuido, como malandro malandreia. Nem cento-e-cinqüenta braças era o eito, jaculação minha." (grifo nosso. ROSA. GSV, vol. 2, 2009, pág. 139)

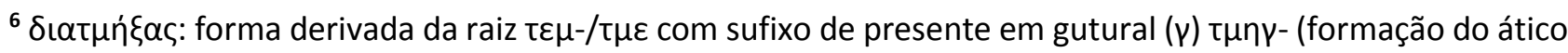
é té $\mu v \omega)$. Utilizamos o arcaísmo "desmear" e acrescentamos no interior da palavra um "i" (epêntese). Assim, com epêntese, Rosa utiliza o verbo "malandrar" como "malandreiar": "Disparo que eu dava, era catando mover alheio, cujo descuido, como malandro malandreia." (grifo nosso. ROSA. GSV, vol. 2, 2009, pág. 139) ${ }^{7} \pi \varepsilon \delta$ íov$\delta \varepsilon$ : paragoge do sufixo épico $-\delta \varepsilon$ para expressar movimento. Nossa opção foi o uso do advérbio "afora".

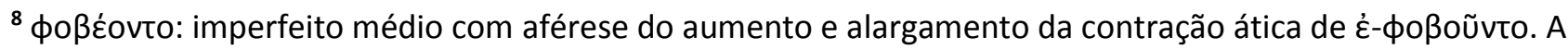
tradução pelo verbo "abispar-se", "precaver-se, acautelar-se", com aférese do "a" e metaplasmo do "b" pelo "v", pretendeu provocar o efeito similar ao utilizado no grego. O verbo pareceu adequado também por ser pronominal e alcançar, por analogia, uma sensação de voz média. - "Manuelzão, a gente não puderam vir antes, este seo Vevelho dava testemunha: um boiadão que chegara e esbarrara, pra travessar o rio, três mil e seiscentas cabeças, boiadama dismensa, cortada em doze golpes, três mil e seiscentas reses, pra jogar n'água, na barra do Abaeté." (grifo nosso. ROSA. Uma estória de amor, vol. 1, 2009, pág. 371) e também: “Lá é uma larga grande. E a ajunta do gado lá é dura... - Sendo 'brabeza', não vale. O que eu posso pagar é menos. Mas a viúva do Antônio Mendes não tem boi?" (grifo nosso. ROSA. Uma estória de amor, vol. 1, 2009, pág. 406)

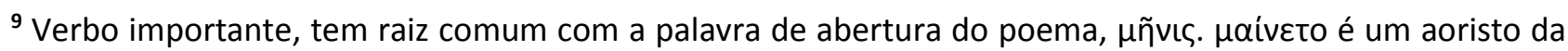
voz média com aférese do aumento. Optamos pelo pronominal "amalucar-se" (que simula uma voz média) ao qual impusemos a aférese: "malucar-se". A genialidade de Guimarães Rosa conciliou a epêntese do verbo e a expressão idiomática "pegou a" em: "Ali esse Treciziano era fraco de paciências; ou será que estivesse curtindo mais sede do que os outros - segundo esse tremor das ventas - e pegou a malucar?" (grifo nosso. ROSA. GSV, vol. 2, 2009, pág. 332) 
${ }^{10}$ Adjetivo que, segundo Liddell-Scott, entre os trágicos é aplicado só em frases épicas. Recorremos a um arcaísmo para traduzi-lo, "galarim" = no apogeu.

Esperamos ter convencido os leitores de que João Guimarães Rosa pode ajudar e ensinar a traduzir Homero: esperamos também ter-lhes apresentado um Homero inédito e vivo, parlante como Riobaldo. Podemos nos alongar por mais cinco versos, do mesmo canto XXI da llíada, quando o Pelida avança para a outra metade do exército debandado, e Hera interfere e auxilia o filho de Tétis na caçada.

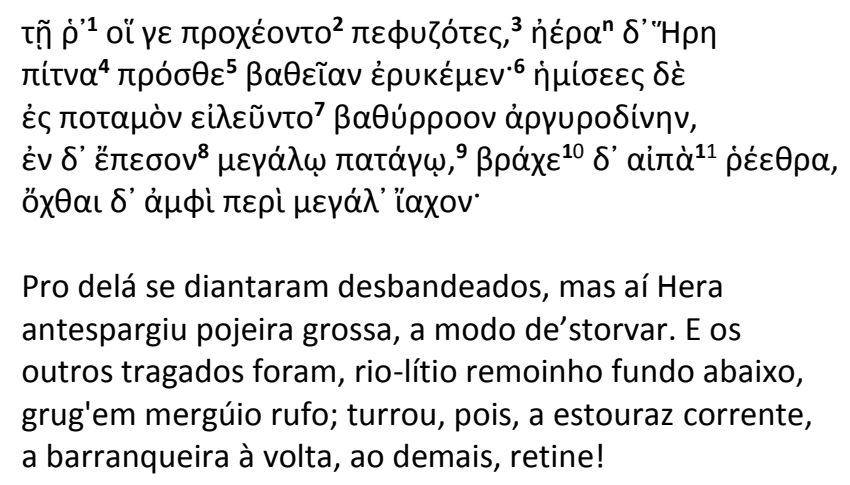

${ }^{1}$ Mantivemos, na tradução, a sinalefa. Tomando Rosa como espelho: “Depois chegava Siá la, a gorda, dona do Atrás-do Alto, meio gira, que ela mesma só falava que andava sumida: - 'Tou p'los matos! Tou p’los matos...'." (grifo nosso. ROSA. Campo Geral, vol. 1, 2009, pág. 337) e, ainda, “- 'Estais p'ra trás... Sabe? Negociei um gado... Mudei meus termos! A ganhar o muito dinheiro - é o que vale... Pó d'ouro em pó...' - o que ele me disse." (grifo nosso. ROSA. GSV, vol. 2, 2009, pág. 394)

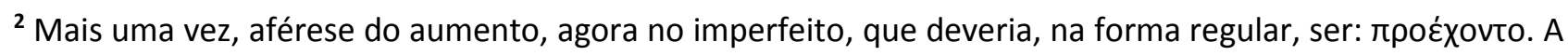
escolha foi "adiantaram-se", com aférese do "a".

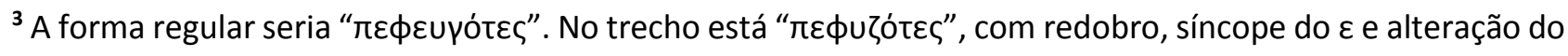

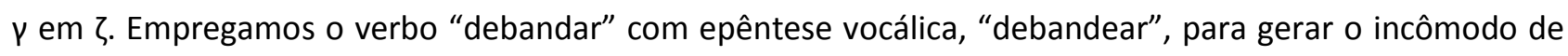
uma forma inusitada, apesar de uma ligeira mudança de significado: "debandar", fugir; "bandear", mudar de lado; acrescentamos igualmente um 's' no prefixo 'de', assim: "desbandear", que, no entanto, não está registrado como forma do português padrão. O processo se espelha no procedimento de Rosa em: “...um boiadão que chegara e esbarrara, pra travessar o rio, três mil e seiscentas cabeças, boiadama dismensa, ..." (grifo nosso. ROSA. Uma estória de amor, vol. 1, 2009, pág. 371); sobre a troca de letras, que não reproduzimos aqui, há exemplos em Rosa: "Boiada chegava? Não, boiada nenhuma, só o Simião Faço, mais seu irmão Jenuário, e outros, voltando daí de rumos, depois de semana." (idem, ibidem)

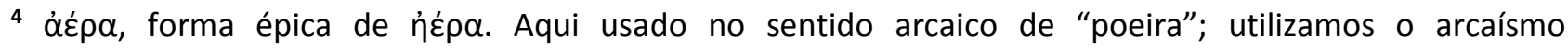
"pojeira/poeira" para evocar efeito similar. Também Rosa faz uso desse arcaísmo: "Tinha de vir, demorão ou jajão. Mas, em que formas? Chão de encruzilhada é posse dele, espojeiro de bestas na poeira rolarem." (grifo nosso. ROSA. GSV, vol. 2, 2009, pág. 273) 
${ }^{5}$ Títva, vocábulo usado somente nessa forma de 3 a pessoa do singular do imperfeito épico sem aumento, a

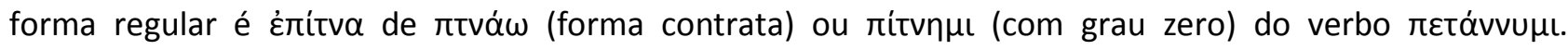
Inventamos e aglutinamos "espargir" com preposição "ante" na forma latina. O verbo tem uma forma única para a 1a pessoa do singular do presente do indicativo, "eu esparjo", e é regularmente usado na 3a pessoa do singular do imperfeito, "ele espargiu". Em Rosa esse verbo é também usado na 3a pessoa do plural: "E entreguei o escrito a Zé Bebelo - minha mão não espargiu nenhum tremor. O que regeu em mim foi uma coragem precisada, um desprezo de dizer; o que disse: - "O senhor, chefe, o senhor é amigo dos soldados do Governo..." E eu ri, ah, riso de escárneo, direitinho; ri, para me constar, assim, que de homem ou de chefe nenhum eu não tinha medo. E ele se sustou, fez espantos." (grifos nossos para dois metaplasmos interessantes, escárneo por escárnio e sustou por sustar mesmo ou assustar. ROSA. GSV, vol.2, 2009, pág. 217-218)

${ }^{6}$ Forma poética, jônica, em lugar de $\pi \rho o ́ \sigma \theta \varepsilon v$. Contemplamos o termo na formação do neologismo "antespargiu". De Rosa: "E o animal dele, o gateado formoso, deu que veio se esbarrar ante mim." (grifo nosso. ROSA. GSV, vol. 2, 2009, pág. 280)

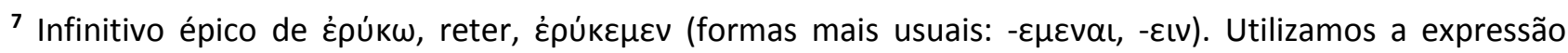
adverbial "a modo de" + o verbo "estorvar" no seu significado arcaico, a saber, "causar estorvo" com aférese, "storvar".

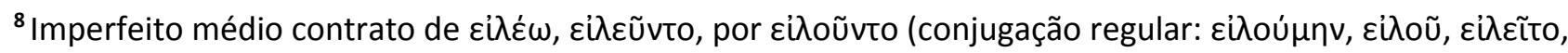

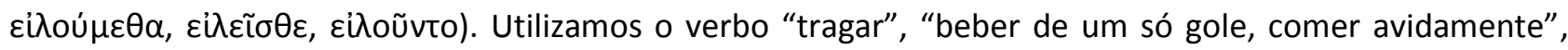
suplente na conjugação do verbo "trazer". Em Rosa, com o sentido de "não tolerar": "E isso de que me serve? Águas, águas. O senhor verá um ribeirão, que verte no Canabrava - o que verte no Taboca, que verte no Rio Preto, o primeiro Preto do Rio Paracatu - pois a daquele é sal só, vige salgada grossa, azula muito: quem conhece fala que é a do mar, descritamente; nem boi não gosta, não traga, eh não." (grifo nosso. ROSA. GSV, vol.2, 2009, pág. 49)

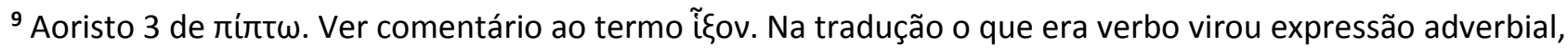
"em mergulho", para a qual utilizamos um metaplasmo por transformação de consoante em vogal ->

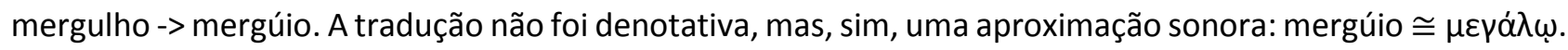
0 adjetivo $\mu \varepsilon \gamma \alpha \dot{\alpha} \omega \omega$, por sua vez, foi traduzido com o verbo "gruir", "correr fazendo algazarra", o significado de barulho intenso se mantém. Em GSV lê-se: “Lhe mostrar os altos claros das Almas: rio despenha de lá, num afã, espuma próspero, gruge; cada cachoeira, só tombos." (grifo nosso. ROSA. GSV, vol.2, 2009, pág. 19) ${ }^{10}$ ratáyos - "estrondo", traduzido por nós como "rufo".

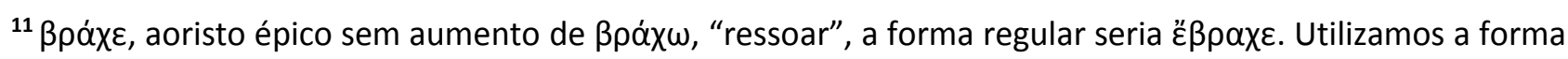
"aturrear" = "fazer barulho aos ouvidos" ou, mesmo, "esturrar" = "rosnar, resmungar, ficar exaltado", ambas com aférese, no caso de "aturrear", supõe-se, além da aférese, síncope da vogal "e". A forma "turrar" existe, significa "bater cabeça, teimar, polemizar". Estamos intencionalmente, trabalhando com todos estes significados. 
12 airós, épico de aỉús, "extremo, alto" que traduzimos para captar a forma particular do épico com um sufixo aumentativo raro para o adjetivo, que se esperaria como "estrondosa", e não "estouraz".

\section{Considerações finais}

Esperamos que, com a apresentação de possibilidades tradutórias por meio de fantasias metaplasmáticas, o leitor julgue razoável afirmar que "um galo sozinho não tece uma manhã"22, ou melhor, que uma só forma de falar não é expressão de uma nação. Afirmamos que Homero - se é que podemos assumir sua individualidade, o que afinal fizemos, para efeito prático de referência - e Guimarães Rosa compuseram suas obras em linguagem artificial, sofisticada, escrita e quiçá nunca falada, mimetizada de oral com plenitude de variantes linguísticas. Nesse contexto, utilizar-se de fantasias metaplasmáticas para traduzir Homero é reconhecer um expediente valioso praticado pelo escritor mineiro, o qual nos serve como modelo para tradução. Linguagem ritmada e repertoriada, com toda a potência lexical e sintática de um povo misturado. Vale o que Monro afirma, a propósito do rapsodo: “Essa multiplicidade de formas gramaticais só pode ser explicada pela consideração de que a linguagem da poesia épica era mais do que um dialeto: era um estilo altamente cultivado e, consequentemente, de certa forma, um estilo convencional, no qual as formas mais antigas eram preservadas pela força da tradição poética." (MONRO, 1828, pág. 53) ${ }^{23}$ Com o mesmo estilo, finalmente, concluímos que, de fato, Rosa, ao espelhar o bardo, ensinou-nos a ler, ouvir e traduzir Homero do grego para o português.

\section{Referências bibliográficas}

CASTRO, Nei Leandro. Universo e vocabulário do Grande Sertão. Rio de Janeiro: Achiamé, 1982.

CHANTRAINE, Pierre. Morphologie historique du grec. Paris: Éditions Klincksieck, 1984.

CHANTRAINE, Pierre. A propos de Thersite. In: L'antiquité classique, Tome 32, fasc. 1, págs. 18-27, 1963.

FRIEDRICH, Paul; REDFIELD, James. Speech as a Personality Symbol: The Case of Achilles. In: Language, Vol. 54, No. 2, pág. 263-288,1978.

LIMA Luiz Costa. 0 controle do imaginário \& afirmação do romance: Dom Quixote, As relações perigosas, Moll Flanders, Tristam Shandy. Companhia das Letras: Rio de Janeiro, 2008.

EDWARDS, Mark W. Homer and Oral Tradition: The Formula, Part I. Oral Tradition, 1/2, págs. 171-230, 1986. Disponível em: https://admin.oraltradition.org/wp-content/uploads/files/articles/1ii/2_edwards.pdf. Acesso em 20/02/ 2020.

GALVÃO, Walnice Nogueira. Rapsodo do sertão: da lexicogênese à mitopoese. In: Cadernos de Literatura Brasileira. v. 12, n. 20-21, pág. 144-186, 2006. Disponível em: https://issuu.com/ims_instituto_moreira_salles/docs/clb_guimar_es_rosa. Acesso em: 20/02/2020.

\footnotetext{
22 Verso de João Cabral de Melo Neto (2008, pág. 319) em "Tecendo a manhã".

23 "This multiplicity of grammatical forms can only be explained by the consideration that the language of Epic poetry was more than a dialect: it was a highly cultivated and consequently in some degree a conventional style, in which older forms were preserved by the force of poetical tradition."
} 
HALPORN, James W.; OSTWALD, Martin; ROSENMEYER, Thomas. The meters of Greek and Latin Poetry. London: Methuen \& Co., 1963.

HAZIN, Elizabeth. De Aquiles a Riobaldo: ação lendária no espaço mágico. In: Revista da Anpoll, no 24, vol 1, pág. 291-303, 2001. Disponível em: https://revistadaanpoll.emnuvens.com.br/revista/issue/view/1/showToc. Acesso em: 20/02/2020.

HOMER. Iliad I. With an essay on Homeric Grammar and notes by David B. Monro. Oxford: Clarendon Press, 1828.

KIRK, G. S. The Iliad: a commentary Vol. I, Books 1-4. Cambridge: University Press, 1985.

LEONEL, Maria Célia de Moraes. O texto rosiano. In: Grácia-Rodrigues, K; Belon, A. R; Rauer. (Org.). 0 universal e o regional: literatura em perspectiva 1. Campo Grande: Ed UFMS, 2009, v. 1, pág. 83-100.

MARTIN, Richard P. The Language of Heroes: Speech and Performance in the Iliad. Ithaca/London: Cornell University Press, 1989.

MARTINS, Ana Luíza Costa. Via e viagens: a elaboração de Corpo de Baile e Grande Sertão: veredas. In: Cadernos de Literatura Brasileira, v. 12, n. 20-21, pág. 187-235, 2006. Disponível em: https://issuu.com/ims_instituto_moreira_salles/docs/clb_guimar_es_rosa. Acesso em: 20/02/2020.

MARTINS, Nilce Sant'Anna. O léxico de Guimarães Rosa. São Paulo: Editora da Universidade de São Paulo, 2001.

MESCHONNIC, Henri. Poética do traduzir. Tradução de Jerusa Pires Ferreira e Suely Fenerich. São Paulo: Perspectiva, 2010.

MESCHONNIC, Henri. Linguagem, ritmo e vida. Extratos traduzidos por Cristiano Florentino. Revisão de Sônia Queiroz. Belo Horizonte: FALE/UFMG, 2006.

MONRO, David B. A Grammar of The Homeric Dialect. Oxford: Clarendon Press, 1891.

MONRO David B. Iliad: books I-XII (with an introduction, a brief Homeric grammar, and notes). Oxford: University Press, 1929.

NETO, João Cabral de Melo. Poesia Completa e Prosa. Rio de Janeiro: Editora Nova Aguillar, 2008.

PHARR, Clyde. Homeric Greek: a book for beginners. Boston/New York/Chicago: D. C. Heath \& Co. Publishers, 1920.

NASCIMENTO, Edna Maria F. S.; COVIZZI, Lenira Marques. João Guimarães Rosa - Homem Plural, Escritor Singular. Rio de Janeiro: Editora Ágora da Ilha, 2a Ed. Mai/2001.

Oxford Latin Dictionary. Oxford: Clarendon Press, 1968.

RICHARDSON, Nicholas. The Iliad: a commentary Volume VI: books 21-24. Cambridge: University Press, 2000. RICOEUR, Paul. Sobre Tradução. Tradução de Patrícia Lavelle. Belo Horizonte, Editora UFMG, 2012

ROSA, João Guimarães. "Grande Sertão: Veredas". Ficção Completa. Vol. 2. Organização de Eduardo F. Coutinho. Rio de Janeiro: Editora Nova Aguilar, pág. 7-395, 2009.

ROSA, João Guimarães. "O espelho". Ficção Completa. Vol. 2. Organização de Eduardo F. Coutinho. Rio de Janeiro: Editora Nova Aguilar, pág. 446-464, 2009.

ROSA, João Guimarães. Entrevista com Walter Friedrich Höllerer. Disponível em: https://www.youtube.com/watch?v=ndsNFE6SP68. Acesso em 02/12/2017.

SILVA, Dora Ferreira da. Às margens de Rosa. In: Cadernos de Literatura Brasileira. v. 12, n. 20-21, pág. 5960, 2006. Disponível em: https://issuu.com/ims_instituto_moreira_salles/docs/clb_guimar_es_rosa. Acesso em: 20/02/2020.

SMYTH, Herbert. Greek Grammar. New York: American Book Company, 1920. 
Souza, Marisa Giannecchini Gonçalves de. Olhos de ver, olhos de enganar. In: Itinerários: Revista de Literatura, n. 8, pág. 113-122, 1995. Disponível em: http://hdl.handle.net/11449/107397. Acesso em: 19/02/2020.

SPERBER, Susi Frankl. As palavras de chumbo e as palavras aladas. In: Floema. Ano II, n. 3, pág. 137-157, 2006. SIDGWICK, Arthur. Homer's Iliad: book XXI. Oxford/Cambridge: Revingtons, 1880.

SILVA, Maria de Fátima. Língua, Identidade e Convivência étnica nas Histórias de Heródoto. In: Humanitas, 61, pág. 59-82, 2009.

STUURMAN, Siep. The Voice of Thersites: Reflections on the Origins of the Idea of Equality. Journal of the History of Ideas, Vol. 65, N. 2, págs. 171-189, 2004.

WEST, M. L. Introduction to Greek Metre. Oxford: Clarendon Press, 1987.

ZILLY, Berthold. Procuro chocar e estranhar o leitor, Grande Sertão: Veredas - a poética da criação e da tradução. In: Revista Fronteiraz. no 19, pág. 4-31, dez. 2017.

ZUMTHOR, Paul. A letra e a voz: A “literatura” medieval. Tradução de Amálio Pinheiro (Parte I) Jerusa Pires Ferreira (Parte II). São Paulo: Companhia das Letras, 1993. 